\title{
Estimating population and livestock density of mobile pastoralists and sedentary settlements in the south-eastern Lake Chad area
}

\author{
Vreni Jean-Richard, ${ }^{1,2}$ Lisa Crump, ${ }^{1,2}$ Abbani Alhadj Abicho, ${ }^{3}$ Ali Abba Abakar, ${ }^{3}$ \\ Abdraman Mahamat II, ${ }^{3}$ Mahamat Bechir, ${ }^{3}$ Sandra Eckert, ${ }^{4}$ Matthias Engesser, ${ }^{4}$ \\ Esther Schelling, ${ }^{1,2}$ Jakob Zinsstag ${ }^{1,2}$ \\ ${ }^{1}$ Swiss Tropical and Public Health Institute, Basel; ${ }^{2}$ University of Basel, Switzerland; \\ ${ }^{3}$ Centre de Support en Santé Internationale, Ndjamena, Chad; ${ }^{4}$ Centre for Development \\ and Environment, University of Bern, Switzerland
}

\begin{abstract}
Mobile pastoralists provide major contributions to the gross domestic product in Chad, but little information is available regarding their
\end{abstract}

Correspondence: Lisa Crump, Swiss Tropical and Public Health Institute, Socinstr. 57, 4051 Basel, Switzerland.

Tel. +41.61.284.8677 - Fax: +41.61.284.8101.

E-mail: lisa.crump@unibas.ch

Key words: Mobile pastoralists; Population density; Livestock density; Lake Chad; Random coordinates.

Ethical considerations: prior to initiating the study, ethical approval was given by the Ethics Commission of the cantons of Basel (Ethikkommission beider Basel, EKBB 316/08) and a research authorization was obtained from the Ministry of Health in Chad (Ministère de la Santé Publique, No 571/MSP/SE/SG/DGAS/2010).

Acknowledgements: the authors would like to thank the study participants and their families for openness to participate in the interviews. Our partners in N'Djaména, the Centre de Support en Santé Internationale (CSSI), are thanked for invaluable contributions and support. Jan Hattendorf provided significant expertise facilitating the statistical analysis. The ASTER L1B data product used to generate the NDVI images is courtesy of the online Data Pool at the NASA Land Processes Distributed Active Archive Center (LP DAAC), USGS/Earth Resources Observation and Science (EROS) Center, Sioux Falls, South Dakota (https://pdaac.usgs.gov/data_access).

Funding: The Swiss National Science Foundation is greatly appreciated for generous financial support.

Received for publication: 7 January 2015.

Revision received: 6 March 2015.

Accepted for publication: 14 March 2015.

(C) Copyright V. Jean-Richard et al., 2015

Licensee PAGEPress, Italy

Geospatial Health 2015; 10:307

doi:10.4081/gh.2015.307

This article is distributed under the terms of the Creative Commons Attribution Noncommercial License (by-nc 3.0) which permits any noncommercial use, distribution, and reproduction in any medium, provided the original author(s) and source are credited. demography. The Lake Chad area population is increasing, resulting in competition for scarce land and water resources. For the first time, the density of people and animals from mobile and sedentary populations was assessed using randomly defined sampling areas. Four sampling rounds were conducted over two years in the same areas to show population density dynamics. We identified 42 villages of sedentary communities in the sampling zones; 11 (in 2010) and 16 (in 2011) mobile pastoralist camps at the beginning of the dry season and 34 (in 2011) and 30 (in 2012) camps at the end of the dry season. A mean of 64.0 people per $\mathrm{km}^{2}$ (95\% confidence interval, 20.3-107.8) were estimated to live in sedentary villages. In the mobile communities, we found 5.9 people per $\mathrm{km}^{2}$ at the beginning and 17.5 people per $\mathrm{km}^{2}$ at the end of the dry season. We recorded per $\mathrm{km}^{2}$ on average 21.0 cattle and 31.6 small ruminants in the sedentary villages and 66.1 cattle and 102.5 small ruminants in the mobile communities, which amounts to a mean of 86.6 tropical livestock units during the dry season. These numbers exceed, by up to five times, the published carrying capacities for similar Sahelian zones. Our results underline the need for a new institutional framework. Improved land use management must equally consider the needs of mobile communities and sedentary populations.

\section{Introduction}

There are an estimated 200 million pastoralists worldwide (Aboud $e t$ al., 2012), 50 million of which are estimated to live in sub-Saharan Africa (Rass, 2006). In Chad, one of the poorest countries of the world, the 2009 national census describes about 388,000 mobile pastoralists, approximately $3.5 \%$ of the total population (Ministère de l'Economie et du Plan, Institut National de la Statistique, des Etudes Economiques et Démographiques, 2010), while other authors estimate the number to be up to 2 million (Thornton et al., 2002; Rass, 2006). Mobile pastoralist communities produce about half of the national meat production, while owning about half of the country's livestock (Rass, 2006). The contribution to the gross domestic product (GDP) from livestock is recently about 18\% (Ministère de l'Elevage et des Ressources Animales du Tchad, 2008), while before the exploitation of petrol it was thought to be nearly $34 \%$ (Hatfield and Davies, 2006). A published estimate suggests about 10 to 20 animals per $\mathrm{km}^{2}$ on the Chadian side of Lake Chad (Thornton et al., 2002), which is low compared to recent observations. The Ministry of Livestock in Chad estimated that 8.1 million people, about $80 \%$ of the population, were living in rural areas in 2003 , with at least 7 million cattle, 3 million camels and 8 million small 
ruminants nationwide. Of all livestock, $80 \%$ are kept in partly mobile production systems (Ministère de l'Elevage et des Ressources Animales du Tchad, 2008).

In the South-Eastern Lake Chad area, there are several ethnic groups of mobile pastoralists with different lifestyles, all of whom experience very restricted access to social services, especially health services. Local health care structures are not conceptualized to cover mobile populations, and there are cultural and language related access problems in addition to discrimination (Fokou et al., 2004). A preliminary study on vaccination coverage showed that livestock were more fully immunized than children under the age of five, none of whom had received the full course of recommended childhood vaccinations. Subsequently, a program of simultaneous vaccination of livestock and children was implemented from 2000 through 2004 (Schelling et al., 2005). To quantify the impact of this campaign on coverage, demographic information about the specific population was needed but not available (Schelling et al., 2007). Indeed, demography of pastoral societies is little studied in general and the data are usually of poor quality. Frequently, mobile pastoralists are not included in demographic assessments (Homewood and Randall, 2009). Nevertheless, this information is essential for planning of social development, land management and social services, in particular health services.

Historically, demographic assessments of mobile pastoralists were aimed at generating information about fertility and mortality rather than population size and density, as in Hampshire and Randall (2000). Few approaches have been described to comprehensively estimate population numbers with regard to mobile pastoralists. The water point approach uses data collected at wells and water bodies utilized by mobile pastoralist livestock, but there are logistical issues with incomplete numbers due to use of multiple water points, variation in migration routes and the difficulty to cover all water points serving an area (Kalsbeek, 1986). Census by airplane is an alternative, but information must still be validated on the ground (Ministère de l'Elevage et des Ressources Animales, 1993). The method shows little promise in areas with many trees, where people and animals rest for protection from the sun. In the south-eastern Lake Chad area, Weibel et al. (2008) tested an alternative method using random transects adapted from the capture-mark-recapture method developed for wildlife (Lindberg and Rexstad, 2006). Biometric fingerprints were used to uniquely identify women and children in mobile pastoralist camps because identification cards were seldom available. Although this method proved feasible, the rate of recapture was too low, about $5 \%$, to conclusively estimate the size of dynamic populations, which migrate across several countries (Weibel et al., 2008).

A small-scale mobile demographic surveillance system covering about 600 people was implemented from 2010 to 2012 in the study area to test the feasibility of human and animal surveillance using mobile communication technology. The method proved to be low-cost, well accepted by the target population and produced consistent, reliable results on life events such as births of people as well as livestock (JeanRichard et al., 2014). Even so, it was not possible to make any estimates about the number of people or animals in an area at a given point in time. However, in the absence of total population numbers, density estimates of people and animals can be substituted as a basis for coordinating and governing sustainable use and allocation of natural resources. The aim of this study was to provide information about the spatial dynamics of people and animals in the south-eastern Lake Chad area to better estimate the need for human and animal health interventions, seasonal food aid and schooling. Additionally, we aimed to assess the land use pressure of livestock in pastoral areas.

\section{Materials and Methods}

\section{Study area}

The normalized difference vegetation index (NDVI) is a measure of the status of the phototsynthethic green vegetation. Figure 1 shows the NDVI derived from two moderate resolution imaging spectroradiometer (MODIS) satellite images downloaded from the NASA Land Processes Distributed Active Archive Center (2011) of the south-eastern shore of Lake Chad. The images were captured in March-April 2011 at the end of the dry season (Figure 1A) and in November-December 2011 at the beginning of the dry season (Figure 1B). The March-April NDVI was used to derive the area covered by water as well as the permanent green area in the study zone. In April 2011, the total area was $4983 \mathrm{~km}^{2}$, of which $173 \mathrm{~km}^{2}$ was water and $493 \mathrm{~km}^{2}$ compromised green vegetation. Thus, $4317 \mathrm{~km}^{2}$ (87\%) were areas without green vegetation at the end of the dry season, reflective of rangeland with only one vegetation growth period per year, during the rainy season.
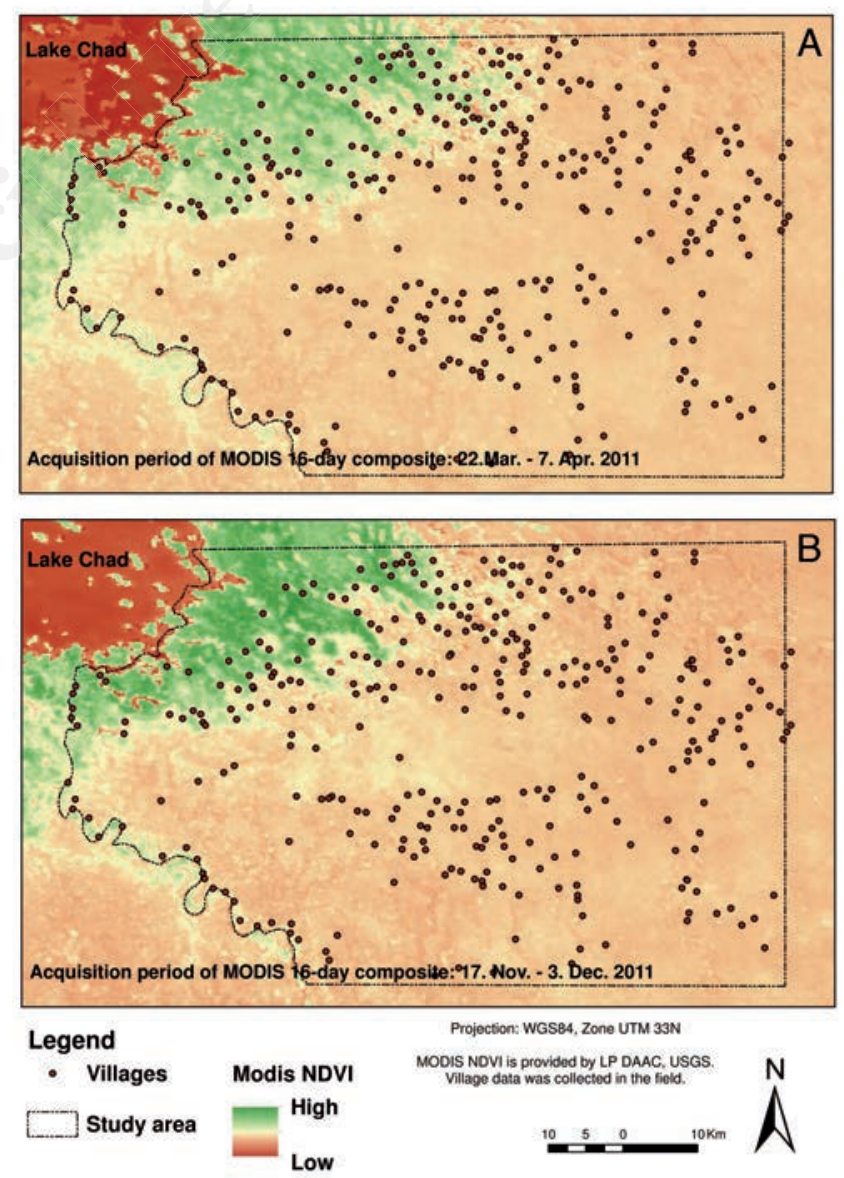

Figure 1. Study zone with green areas at the end of the dry season March-April 2011 (A) and at the beginning of the dry season November-December 2011 (B). Dark green=dense green vegetation; light green and yellow=sparse green vegetation; light orange $=$ dry vegetation; dark orange $=$ sparse dry vegetation to no vegetation; dots=identified permanent settlements. 
Lake Chad has been receding in size over the last 50 years, with an annual reduction rate of $2.3 \%$ (International Union for Conservation of Nature, 2008). The resulting fertile land has attracted the settlement of sedentary communities of subsistence farmers (Planel, 1996; Bechir, 2012), a fact confirming that land use has intensified over the last 30 years. The median year reported for the foundation of permanent settlements was 1982. Similarly, mobile communities indicated their first arrival as 1986 (median), which translates to 25 years at the time of interview for this study. However, some mobile and some sedentary communities were established as recently as the previous year (JeanRichard, 2013). Figure 1 shows the high number of permanent settlements observed in 2011 in the study area. The number of mapped villages is likely to be incomplete, since our recording was not systematic, but rather derived from local knowledge augmented by review of Google Earth maps, and new settlements continue to be established each year.

\section{Methodological approach}

To estimate population density in the study area, 20 random coordinates were generated from a rectangular area which included the study zone and some reserve areas. After the latitude/longitude coordinates were converted into an equal-area projection, a sequence of points was randomly generated within the boundary circumscribed rectangle of the shape file. The point generation condition was set as a minimum distance of $5 \mathrm{~km}$ between points, according to the visual scanning protocol described below. Three points outside the study zone were eliminated and the remaining total was 17 .

Each of the remaining points was visited four times, twice at the beginning of the dry season (October - November in 2010 and 2011) and twice at the end of the dry season (April - May in 2011 and 2012). Using a hand-held global positioning system (GPS) device (Garmin eTrex 10), the selected points were located. The area around the points, including a 500-m radius, was scanned visually. Collaborators with extensive local knowledge visually scanned the area on both sides of the route for camps and settlements. A distance of $1 \mathrm{~km}$ was then measured from the original coordinates, and the central point was slowly circled at a $1-\mathrm{km}$ radius. The same procedure was then repeated at a distance of $2 \mathrm{~km}$ (Figure 2). The assumed visibility of $500 \mathrm{~m}$ was a conservative value chosen to ensure identification of all camps and villages, based on a previous study in the area which assumed 1-km visibility (Weibel et al., 2008). With this approach, a circular area, $5 \mathrm{~km}$ in diameter, with its centre at a randomly selected coordinate, was covered. In each random coordinate surveyed $(n=17)$ the total surface surveyed was $19.6 \mathrm{~km}^{2}\left[=(2.5 \mathrm{~km})^{2} \pi\right]$.

When any sign of a camp or village, such as a roaming donkey or fresh droppings from sizeable cattle herds, was noted, the circuit was interrupted, and the research team approached the camp or village, registering its coordinates with the hand-held GPS device. If only a single person was seen, he/she was asked for directions to nearby camps or settlements. After the location had been registered, permission for an interview was requested, and if the camp or village leader was available, the interview was conducted immediately. Otherwise, an appointment was sought, usually for early morning the next day, and then the driving circuit was resumed at the previous point of deviation. The inclusion criterion was that the hut or tent of the village/camp leader (Boulama) was inside the $2.5 \mathrm{~km}$ radius surrounding the random coordinates.

During the interview, the camp leader was informed about the study and asked for oral consent to participate. This approach was dictated by the very high illiteracy rate in the study zone. An interview was conducted with the community leader, who was usually accompanied by male family and community members. Sometimes women also partici- pated. Data from sedentary villages were only collected the first time they were encountered. Interviews began with open questions to assess the livelihood priorities of the communities. Further questions were asked about the population of the community and the livestock owned. A community was defined as all the people travelling with the Boulama during the transhumance, i.e., those for whom he was responsible. For villages, the community included all those for whom the Boulama was responsible. If a village was large enough to be divided into satellite villages, only the satellites where the Boulama was dwelling within the coordinate perimeters were included.

All data were double entered into Microsoft ${ }^{\circledR}$ Access 2002 (Microsoft Corp.; Redmond, USA), and databases were examined with Epi Info ${ }^{\mathrm{TM}}$ 3.5.1 Data Compare program (Centers for Disease Control and Prevention, Atlanta, GA, USA). Discrepancies were corrected, and statistical analysis carried out with Stata IC 10.1 (StataCorp LP, College Station, TX, USA). Finally, the data were compared with data from a longitudinal surveillance study at the household level in the same area (Jean-Richard et al., 2014) for triangulation.

\section{Results}

Data from 42 villages and camps of mobile pastoralists were collected for the repeatedly visited 17 random coordinates. At the beginning of the dry season (October-November), we found 11 mobile pastoralist camps in 2010 and 16 camps in 2011. At the end of the dry season (April-May), we located 34 camps in 2011 and 30 camps in 2012. The median population was 129 people per camp and 167.5 people per village. Mobile pastoralist camps registered much higher numbers of animals, with 500 cattle and 500 small ruminants per camp compared to 30 cattle and 102 small ruminants per village (Table 1).

\section{Density of people and animals}

In the sedentary population, we found an average of 64.0 people per $\mathrm{km}^{2}$ [95\% confidence interval (CI): 20.3-107.8]. The numbers for mobile people were much lower, only 11.7 , which is the average of 5.9 people per $\mathrm{km}^{2}$ at the beginning of the dry season (95\% CI: $\left.2.3-9.5\right)$ and 17.5 people per $\mathrm{km}^{2}$ at the end of the dry season (95\% CI: 10.7-24.3). Livestock from sedentary villages amounted on average to 21.0 cattle

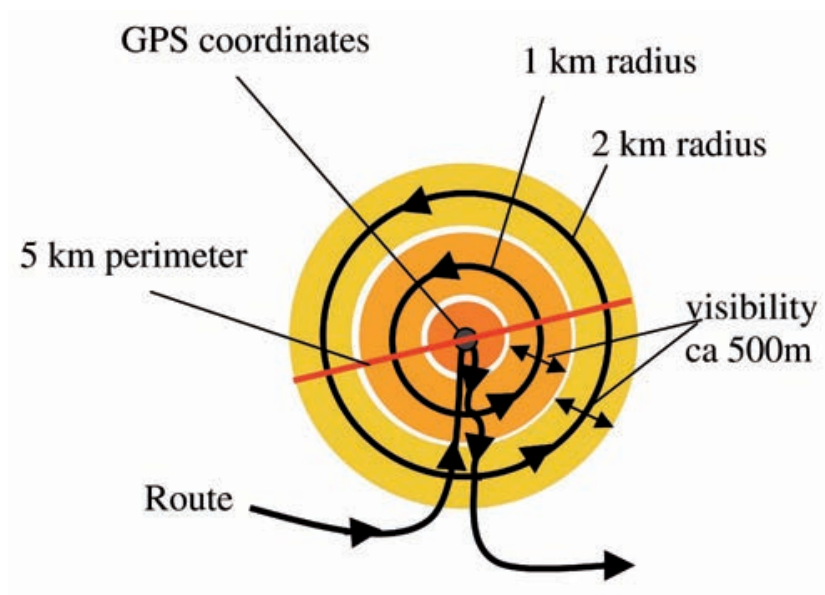

Figure 2. Schematic illustration of sampling method. 
per km² (95\% CI: 1.3-40.7) and 31.6 small ruminants per $\mathrm{km}^{2}$ (95\% CI: 13.1-50.1). The mean values for mobile pastoralist animals were 66.1 cattle per $\mathrm{km}^{2}$ (95\% CI: 41.1-91.2) and 102.5 small ruminants per $\mathrm{km}^{2}$ (95\% CI: 35.2-169.8) (Figure 3). Although the numbers were much smaller than those registered for cattle and small ruminants, camels, donkeys and horses were also present in both sedentary and mobile communities (Table 2).

When animal density is expressed in tropical livestock units (TLU; Cattle=0.7 TLU; camels=1 TLU; small ruminants=0.1 TLU; donkeys=0.5 TLU; horses=0.8 TLU), as described by Jahnke (1982) and utilized by the Food and Agriculture Organization (FAO, 2014), we calculated an average of 74.4 TLUs per $\mathrm{km}^{2}$ during the dry season for cattle and small ruminants. Including camels, donkeys and horses there were an additional 12.2 TLUs per $\mathrm{km}^{2}$, resulting in 86.6 TLU per $\mathrm{km}^{2}$ during dry season.

The CIs of the animal per person ratio for cattle, sheep and goats overlapped with CIs of data collected from households during a longitudinal surveillance study in the same area (Jean-Richard et al., 2014), as shown in Figure 4. However, the household level data represent only cattle breeding families, who remained in the study zone year round selected by convenience sampling, while the camp data represent all mobile pastoralists in the area at the time of sampling.

\section{Discussion}

To our knowledge, this study is the first to present information about the density of both people and livestock on the Chadian side of Lake Chad. Importantly, we found the densities recorded at the end of the dry season notably high. Compared to our results, the livestock estimates by Thornton et al. (2002) seem very low for the Chadian side of the lake (maximum of 10 to 20 animals per $\mathrm{km}^{2}$ ). Although these authors do not report human densities, it is reasonable to think that they would also have been low.

Assuming an average rainfall of $400 \mathrm{~mm}$ per year for the Chadian side of the lake basin (FAO, 1997), which is still higher than data from the World Bank (2013) for the study area, the carrying capacity would be comparable to the estimates of 14 to $23 \mathrm{TLU} / \mathrm{km}^{2}$ for other areas in the Sahel zone (Leeuw and Tothill, 1990) with similar rainfall and a single rainy season (Wylie et al., 1987; Hiernaux, 1982; Le Houérou and Hoste, 1977; Pratt et al., 1977). We acknowledge that the concept of carrying capacity continues to be debated (Scoones and Graham, 1994), nevertheless, the contrast between the estimated carrying capacities and the high TLU/ $\mathrm{km}^{2}$ found in our study area is remarkable. It is reasonable to further conclude that fodder could be insufficient for the number of animals, with overuse of pastoral resources contributing to emaciation in animals and, further, malnutrition of people in the area.

Arguably, over $13 \%$ of the study area vegetation is growing throughout the year (Figure 1). Importantly, however, an increasing proportion of this land is in agricultural use and no longer available to pastoralists. Additionally, many areas of the green zones are taken up by villages, further decreasing accessible pasture areas to mobile pastoralists. Our calculations considered the entire surface area of the surveyed coordinates, even though some areas were not available for grazing livestock. Therefore, this method was considered to be a conservative estimate.

Although they are well aware of the problem, pastoralists are reluctant to reduce herd sizes. The strategy of owning as many animals as possible is reinforced by insecurity, thereby providing a means of resilience to mobile pastoralists through balancing losses from disease and lack of feed due to pasture unavailability. The Chadian government
Table 1. Number of villages/camps with median population and livestock numbers per village/camp.

\begin{tabular}{lccc} 
Population and livestock & Place $^{\circ}$ & $\begin{array}{c}\text { Median } \\
\text { population }\end{array}$ & $\begin{array}{c}25-75 \% \\
\text { quartiles }\end{array}$ \\
People & Camp & 129 & $65-210$ \\
& Village & 167.5 & $76-420$ \\
Cattle & Camp & 500 & $200-1100$ \\
& Village & 30 & $0-150$ \\
\hline \multirow{2}{*}{ Small ruminants } & Camp & 500 & $160-1500$ \\
& Village & 102 & $50-420$ \\
\hline
\end{tabular}

${ }^{\circ}$ Total number of camps $=91$; total number of villages $=42$.

Table 2. Animal density per $\mathrm{km}^{2}$ in villages and mobile communities.

$\begin{array}{lccc}\text { Type of community } & \text { Animal } & \text { Mean per } \mathbf{k m}^{2} & 95 \% \mathrm{CI} \\ \text { Village } & \text { Camel } & 0.2 & 0.0^{\circ}-0.6 \\ & \text { Donkey } & 5.7 & 2.0-9.5 \\ & \text { Horse } & 1.9 & 0.6-3.2 \\ \text { Mobile community } & \text { Camel } & 4.1 & 0.0^{\circ}-9.0 \\ \text { (mean between beginning } & \text { Donkey } & 4.6 & 2.6-6.6 \\ \text { and end of dry season) } & \text { Horse } & 1.5 & 0.9-2.0 \\ \text { CI, confidence interval. }{ }^{\circ} \text { Confidence limits truncated at } 0 . & \end{array}$

$\mathrm{Cl}$, confidence interval. ${ }^{\circ}$ Confidence limits truncated at 0 .

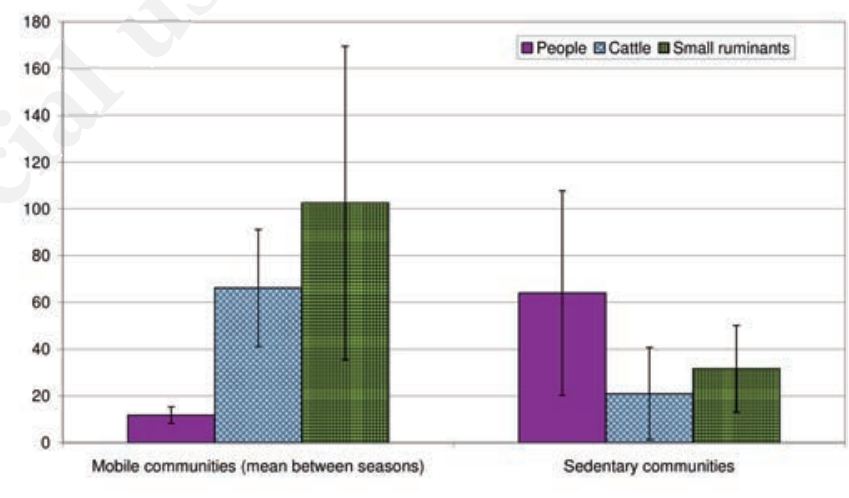

Figure 3. Density of people and animals per $\mathrm{km}^{2}$ in mobile vs sedentary pastoralist camps and villages.

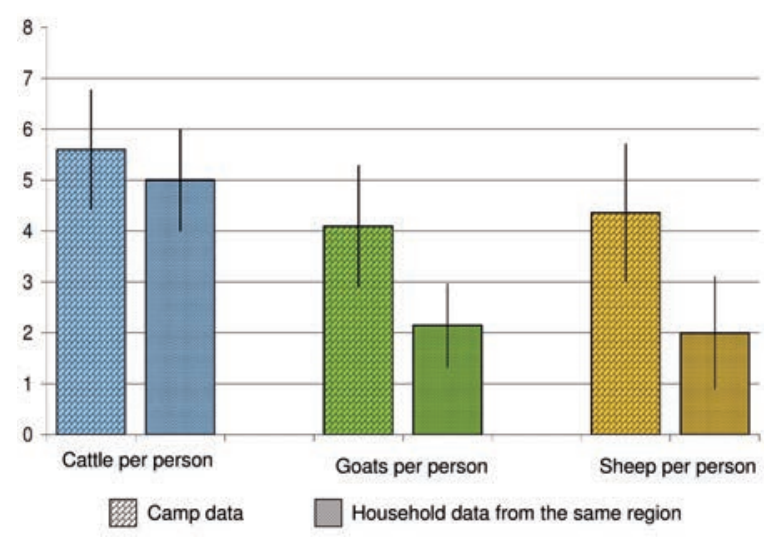

Figure 4. Comparison of livestock numbers per person between camps (data are based on longitudinal household data from the same area and time period by Jean-Richard et al., 2014) 
estimates that the animal numbers in the Sahelian zone of Chad have grown from 12 million TLU in 2000 to 16 million TLU in 2010, an increase of $33 \%$, and it is expected that the number will further increase to 21 million TLU by 2020 (Ministère de l'Elevage et des Ressources Animales du Tchad, 2008). Increasing livestock numbers in the area were also observed by Wiese (2006).

Sedentarization of pastoralist families is frequently observed. Some mobile communities also stated that they desire to become sedentary but have been unable to obtain land to settle and farm. Other communities purchase land for grazing animals, but it is not sufficient to maintain their herds over an entire year.

The lack of access to pastures and the increasing pressure from sedentary communities on mobile populations and lifestyle was strongly emphasized by mobile pastoralist leaders (Jean-Richard, 2013). A stable political system and functional infrastructure are needed for mobile pastoralists to provide alternatives to maximising herd size. Regulations for pasture and agricultural land use must be developed and implemented and veterinary services must be improved in order to guarantee health maintenance in smaller herds. Also, mobile pastoral- ists must have access to stable equitable, alternative investments, for example, land or estate property and bank accounts, as a pre-condition for a meaningful change of strategy towards more sustainable and equitable land management.

The situation in the study area parallels the tragedy of the commons, described long ago by Hardin (1968) in the context of a system in which rational individuals have freedom to use common resources to pursue individual gain without imposed limits. It was used as a justification to privatise rangeland, which has paradoxically not led to the anticipated higher productivity (Fratkin and Mearns, 2003; Scoones and Graham, 1994; Turner, 1993). Hardin's assumption of complete absence of regulations is rarely true in reality, since most rangeland areas are governed by traditional regulations, which allocate at least some rights in this connection (Peters, 1994; Turner, 1993; Bromley, 1992). However, the lack of binding regulations is increasingly becoming an important issue in many places including the study area (Figure 5). There is clearly a need for a new integrated institutional framework to regulate the governance of natural resources, especially with regard to pasture and water access.

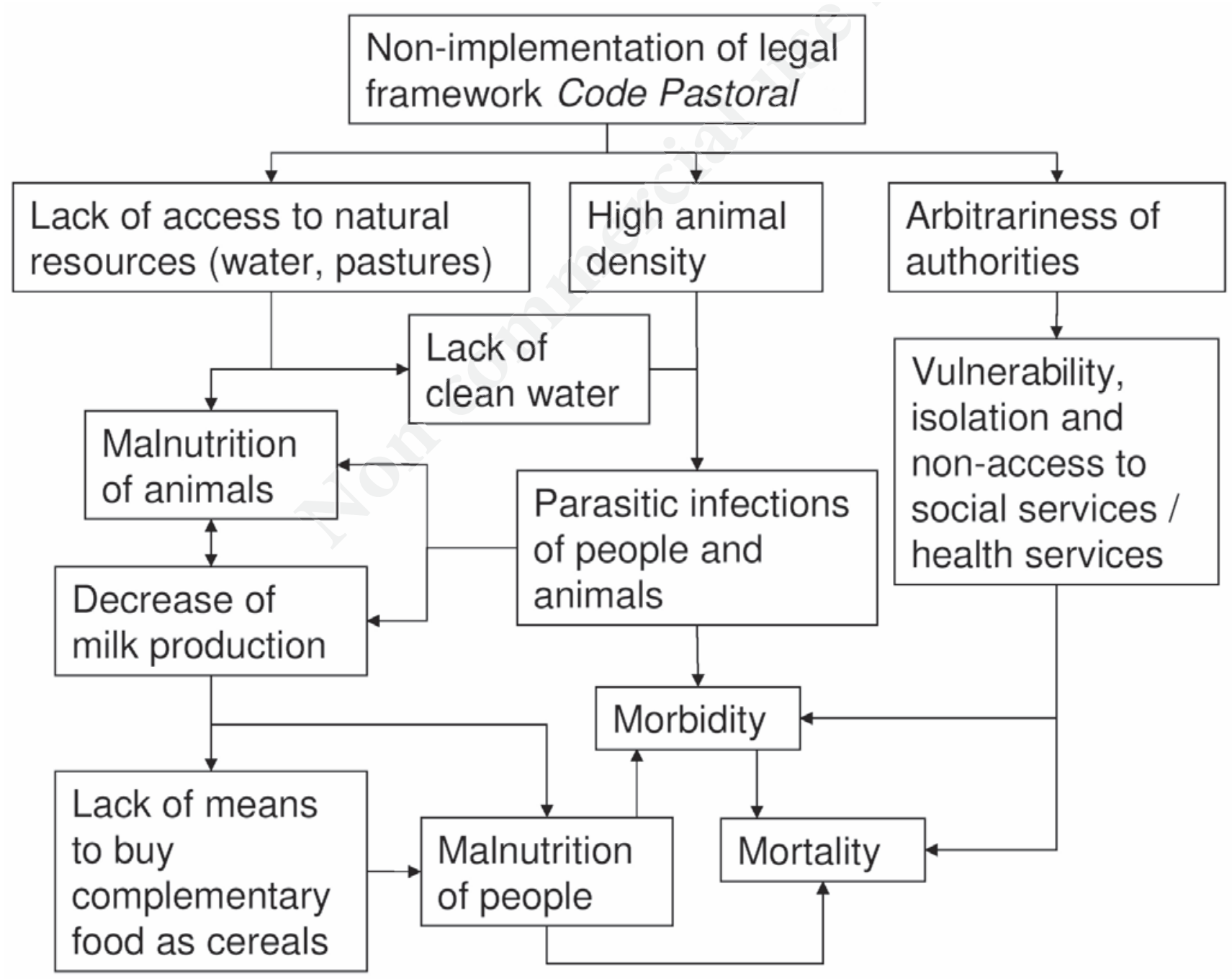

Figure 5. Implications of non-implementation of an institutional framework for mobile pastoralists (based on Bechir, 2012). 


\section{Conclusions}

Bechir (2012) called for the implementation of a minimum service package to pastoralists as a condition for social peace, food security and resource accessibility. Such a package should provide for basic human and animal healthcare as well as education, and it emphasizes the need for a legal and binding institutional framework for mobile pastoralism. Moreover, pastoralists should be encouraged to destock their herds with acceptable, locally adapted measures (Bechir, 2012).

The call for a new institutional framework has been made repeatedly in mobile pastoralist research in the south-eastern Lake Chad area (Montavon et al., 2013; Bechir, 2012; Wiese, 2006; Fokou et al., 2004). Regulations to legislate land use and pastoralist movement cannot be imposed from the outside, but must rather be actively developed by the Government and Ministries with participation from representatives of the concerned populations. In Chad, a new Pastoral Code has been drafted and is being reviewed by the Ministry of Livestock; however, there are many conflicting interests involved, and progress has been very slow (International Crisis Group, 2014). Although a cross-sectoral project for the benefit of mobile pastoralists is being undertaken by the Ministry of Planning, the frequent turnover of ministers has slowed down decision processes considerably. Moreover, the initial concept of an inter-sector policy involving health, education and environment cannot be easily put into action because the Ministries generally restrict planning to their own sector. The Ministry of Health currently has a Directorate dealing with the health of hard-to-reach populations and this Directorate should take the lead in coordination between different Ministries concerned. Recently, the demand for a new legal framework has been taken up by an association of young pastoralists (Association des Jeunes Pasteurs du Tchad) that comprises several ethnic groups with the aim to politically represent the mobile pastoralist community, and they have been recognized by the national Parliament. They have anecdotal success in the areas of health service provision, legal assistance and information exchange through networking.

\section{Limitations of the study}

Our data should be interpreted with caution, because all population and herd numbers are reported data which cannot be readily verified despite long tradition of collaboration between researchers and the local population, which has so far provided a trustworthy basis for data collection. Possibly, animal numbers were too large for a valid count. However, it is more likely that the data concerning animal numbers was underestimated since mobile pastoralists are reluctant to answer questions concerning numbers of livestock based on concern that the data might be used for taxation purposes (Homewood and Randall, 2009). Notably, the reported animal per person ratio is comparable to numbers recorded during a small-scale demographic survey within the communities (Jean-Richard et al., 2014). Finally, data were highly dynamic over the collection period of two consecutive years. A longer study period might have led to a wider range of registered outcomes, thus yielding a more accurate estimate over time.

\section{References}

Aboud A, Said M, Notenbaert A, de Leeuw J, Gitau J, Manzano P, Daves J, Roba G, Omondi S, Odhimabo M, 2012. Natural resource management and biodiversity conservation in the drylands of Eastern and Central Africa. Association for Strengthening Agricultural Research in Eastern and Central Africa ed., Entebbe, Uganda.

Bechir M, 2012. Etude épidémiologique de la malnutrition en milieu nomade au Tchad: diagnostic et approche d'interventions. Degree Thesis. University of Basel, Basel, Switzerland.

Bromley D, 1992. Making the commons work: theory, practice, and policy. ICS Press, London, UK.

FAO, 1997. Irrigation potential in Africa: a basin approach. Available from: http://www.fao.org/3/a-w4347e/index.html\#Contents

FAO, 2014. Livestock and environment toolbox. Available from: http://www.fao.org/ag/againfo/programmes/en/lead/toolbox/Mixed1/ TLU.htm

Fokou G, Haller T, Zinsstag J, 2004. Identification of institutional factors affecting the well-being of sedentary and nomadic populations living in the Waza-Logone flood plain along the border between Cameroon and Chad. Med Trop (Mars) 64:464-8.

Fratkin E, Mearns R, 2003. Sustainability and pastoral livelihoods: lessons from East African Maasai and Mongolia. Hum Organ 62:11222 .

Hampshire K, Randall S, 2000. Pastoralists, agropastoralists and migrants: interactions between fertility and mobility in northern Burkina Faso. Pop Stud-J Demog 54:247-61.

Hardin G, 1968. The tragedy of the commons. Science 162:1243-8.

Hatfield R, Davies J, 2006. Global review of the economics of pastoralism. IUCN, Nairobi, Kenya.

Hiernaux P, 1982. Méthode d'evaluation du potential fourrager de parcour sahelien. Centre for Agrobiological Research, Wageningen, The Netherlands.

Homewood K, Randall S, 2009. Ecology of African pastoralist societies. Ohio University Press, Athens, OH, USA.

International Crisis Group, 2014. The security challenges of pastoralism in Central Africa. International Crisis Group, Brussels, Belgium.

International Union for Conservation of Nature, 2008. Climate change in the Lake Chad, Niger, and Senegal Basin; Lake Chad Basin analysis. IUCN, Gland, Switzerland.

Jahnke H, 1982. Livestock production systems and livestock development in tropical Africa. Kieler Wissenschaftsverlag Vauk, Kiel, Germany.

Jean-Richard V, 2013. Crowding at Lake Chad: an integrated approach to demographic and health surveillance of mobile pastoralists and their animals. Diss. Thesis. University of Basel, Basel, Switzerland.

Jean-Richard V, Crump L, Daugla D, Hattendorf J, Schelling E, Zinsstag $\mathrm{J}, 2014$. The use of mobile phones for demographic surveillance of mobile pastoralists and their animals in Chad: proof of principle. Glob Health Action 7:23209.

Kalsbeek W, 1986. Nomad sampling: an analytic study of alternative design strategies. Am Stat Assoc 164-9.

Leeuw P, Tothill J, 1990. The concept of rangeland carrying capacity in sub-Saharan Africa - myth or reality. Overseas Development Institute, London, UK.

Le Houérou H, Hoste C, 1977. Rangeland production and annual rainfall relations in the Mediterranean Basin and in the African SaheloSudanian zone. J Range Manage 30:183-9.

Lindberg M, Rexstad E, 2006. Capture-recapture sampling designs. John Wiley \& Sons, London, UK.

Ministère de l'Elevage et des Ressources Animales du Tchad, 2008. Plan national de dévéloppement de l'elevage (2009-2016). Ministère de l'Elevage et des Ressources Animales du Tchad, N'Djamena, Tchad.

Ministère de l'Economie et du Plan, Institut National de la Statistique, 
lies, Chad. Emerg Infect Dis 13:373-9.

des Etudes Economiques et Démographiques, 2010. Deuxième recensement général de la population et de l'habitat 2009. Ministère de l'Economie et du Plan, Institut National de la Statistique, des Etudes Economiques et Démographiques, N'Djamena, Tchad.

Ministère de l'Elevage et des Ressources Animales, 1993. Survols aériens à basse altitude du cheptel, des habitations humaines et des ressources partorales dans la 'zone d'organisation pastorale', Tchad. Resource Inventory and Management, Jersey, Channel Islands, UK.

Montavon A, Jean-Richard V, Bechir M, Daugla D, Abdoulaye M, Bongo Naré R, Diguimbaye-Djaibé C, Alfarouk I, Schelling E, Wyss K, Tanner M, Zinsstag J, 2013. Health of mobile pastoralists in the Sahel - assessment of 15 years of research and development. Trop Med Int Health 18:1044-52.

NASA Land Processes Distributed Active Archive Center, 2011. ASTER L1B. USGS/Earth Resources Observation and Science (EROS) Center. Available at https://pdaac.usgs.gov/data_access

Peters P, 1994. Dividing the commons: politics, policy, and culture in Botswana. University of Virginia Press, Charlottesville, VA, USA

Planel S, 1996. Pasteurs et agriculteurs : une cohabitation difficile. Etude d'un espace agropastoral au sud du lac Tchad. Mémoire de maîtrise en géographie. University of Paris, Paris, France.

Pratt D, Blackie J, Gwynne M, 1977. Rangeland management and ecology in East Africa. Hodder and Stoughton, London, UK.

Rass N, 2006. Policies and strategies to address the vulnerability of pastoralists in sub-Saharan Africa. FA0, Geneva, Switzerland.

Schelling E, Bechir M, Ahmed M, Wyss K, Randolph T, Zinsstag J, 2007. Human and animal vaccination delivery to remote nomadic fami-
Schelling E, Daoud S, Daugla D, Diallo P, Tanner M, Zinsstag J, 2005. Morbidity and nutrition patterns of three nomadic pastoralist communities of Chad. Acta Trop 95:16-25.

Scoones I, Graham 0, 1994. New directions for pastoral development in Africa. Dev Pract 4:188-98.

Thornton P, Kruska R, Henninger N, Kristjanson P, Reid R, Atieno F, Odero A, Ndegwa T, 2002. Mapping poverty and livestock in the developing world. International Livestock Research Institute, Nairobi, Kenya.

Turner M, 1993. Overstocking the range: a critical analysis of the environmental science of Sahelian pastoralism. Econ Geogr 69:402-21.

Weibel D, Schelling E, Bonfoh B, Utzinger J, Hattendorf J, Abdoulaye M, Madjiade T, Zinsstag J, 2008. Demographic and health surveillance of mobile pastoralists in Chad: integration of biometric fingerprint identification into a geographical information system. Geosp Health 3:113-24.

Wiese M, 2006. Health-vulnerability in a complex crisis situation. Implications for providing health care to a nomadic people in Chad. Verlag für Entwicklungspolitik, Hemsbach, Germany.

World Bank, 2013. Climate change knowledge portal for development practitioners and policy makers. Available from: http://sdwebx.worldbank.org/climateportal/index.cfm?page=country_historical_climate\&ThisRegion=Africa\&ThisCCode=TCD

Wylie B, Harrington J, Pieper R, Maman A, Denda I, 1987. 1987 Pasture assessment early warning system. Niger Integrated Livestock Production Project, Ministry of Animal and Water Resources, Niamey, Niger. 